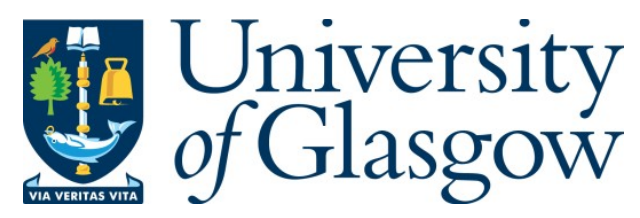

Carter, J. A., and Palermos, S. O. (2016) Is having your computer compromised a personal assault? The ethics of extended cognition. Journal of the American Philosophical Association, (doi:10.1017/apa.2016.28).

There may be differences between this version and the published version. You are advised to consult the publisher's version if you wish to cite from it.

http://eprints.gla.ac.uk/133315/

Deposited on: 4 January 2017

Enlighten - Research publications by members of the University of Glasgow http://eprints.gla.ac.uk 


\title{
THE ETHICS OF EXTENDED COGNITION: IS HAVING YOUR COMPUTER COMPROMISED A PERSONAL ASSAULT?
}

\author{
J. Adam Carter \& S. Orestis Palermos ${ }^{1}$ \\ University of Edinburgh
}

\begin{abstract}
Philosophy of mind and cognitive science (e.g., Clark and Chalmers 1998; Clark 2010; Palermos 2014) have recently become increasingly receptive to the hypothesis of extended cognition, according to which external artifacts such as our laptops and smartphones can-under appropriate circumstances-feature as material realisers of a person's cognitive processes. We argue that, to the extent that the hypothesis of extended cognition is correct, our legal and ethical theorising and practice must be updated, by broadening our conception of personal assault so as to include intentional harm towards gadgets that have been appropriately integrated. We next situate the theoretical case for extended personal assault within the context of some recent ethical and legal cases and close with some critical discussion.
\end{abstract}

\section{Introduction}

An unnamed, third party entity has found a backdoor to San Bernardino shooters' iPhone, just in time to avoid one of history's biggest technological clashes. With the F.B.I. and White House having legally pushed tech-giant Apple to hack its own software's security system, they have effectively demanded from Apple to not only give up, but essentially revert decades worth of efforts in advancing privacy and cybersecurity. By appealing to First Amendment rights and the right to privacy, Apple has stood on principle despite the enormous legal risks. Luckily, said unnamed, deus ex machina entity has made its appearance, the court showdown has been cancelled and the crisis has been abated. Or has it?

In this climate of technological cold war, the time is ripe to focus on the nature of our gadgets and the information stored in them..$^{2}$ Just how close are the parallels between the information 
individuals have traditionally stored in their biological brains and the information that is now being stored in their gadgets, and what might such parallels mean with respect to the ethical and legal protection we should afford our 'smartifacts'?

First of all, there is a personal question we may ask ourselves: How would we feel, and what actions would we take, if someone intentionally broke our phone, stole our smart watch or hacked our laptop, in a way that significantly undermined our ability to organize our lives? Suppose, for example, that someone compromised the gadgets you rely on daily, such that your diary appointments, your contacts list, photos, system preferences and functionalities, research notes, folders, reminders, push on notifications and so on has all turned into a jumbled, corrupted mess of disorganized data. Would it feel like one merely damaged your property? Or might the situation perhaps be worse, as if someone had actually assaulted you?

Personal assault is a particular form of harm, which involves the actual or intended use of force to another person without his consent. ${ }^{3}$ As a concept, assault has an important history, both ethically and legally. For one thing, the freedom from a violation of bodily integrity is at the very heart of one's right to self-ownership ${ }^{4}$ and personal autonomy. ${ }^{5}$ Legally, assault has long been designated as a special category of offence, one whose status in criminal and civil law is distinct from the offence one commits by merely damaging another's property. Even though legal complexities to do with assault have typically clustered around the question of intent, ${ }^{6}$ the part about the person is often taken for granted. One obvious reason for this is that hardly anyone ever questions, at least for most practical purposes, the boundaries of a person. But where does a person really end? 
Consider the following question: What makes the difference between whether I've intended to use force against your person as opposed to merely your property? Perhaps it just seems obvious. Here's one explicit answer, which has become a precedent in UK law:

The body of the victim includes all parts of his body, including his organs, his nervous system and his brain. Bodily injury therefore may include injury to any of those parts of his body responsible for his mental and other faculties. ${ }^{7}$

This is more or less unsurprising. However, notice that the above two statements capture subtly different ideas. While the first clause attempts to spell out what one's body (and thereby bodily injury) consists in reductively, by pointing out specific organismic parts, the second clause does so in a functionalist way: ${ }^{8}$ If a part of one is responsible for (e.g., by being a material realiser of) one's mental or other faculties, then you can harm an individual by injuring whatever materially realises such faculties.

Normally, what is responsible for an individual's faculties are exactly the sort of organismic parts that are listed as examples in the first statement: organs, the central nervous system and the brain. Yet the second (functionalist) clause leaves it open as to whether all faculties that make up one's person can be reduced to one's biological organism or whether, possibly, there could be more to it. In other words, that it might be possible to harm the body of an individual by harming whatever may underwrite that individual's mental and other faculties.

On this more liberal and open-ended way of thinking about the relevance of the person to assault, one uses force against another's person if one injures (along with physical body parts) one's powers, by harming whatever may underwrite these powers. In discussions of the importance of 
freedom from violation of self-ownership, we find a similar implicit functionalism. As political philosopher Gerald Cohen (1995) remarks, the very concept of self-ownership holds that:

[...] each person enjoys, over himself and his powers, full and exclusive rights of control and use, and therefore owes no service or product to anyone else that he has not contracted to supply.

Similarly, Charles Taylor (1991) has argued that a satisfying criterion for what it is to violate an individual's personal autonomy should advert to a conception of personhood which does not simply identify the person with her biological constitution. ${ }^{10}$ As Taylor (1991) remarks:

In any number of ways we are constituted by factors that lie beyond our reflective control but which nonetheless structure our values, thoughts, and motivations (1991, $33 \mathrm{f}){ }^{11}$

In none of these discussions of the relevance of the person to either the legal conception of assault nor to ethical discussions of the significance of freedom from harm to one's person, do we find a necessary reductive identification of an individual's person with her biological constitution. Rather, it seems that what makes freedom from assault have the ethical and legal significance that it has is that freedom from harm to one's physical constitution and/or her powers or capacities (including her capacities for reflection, thought, and the structuring of her values) has a distinctive kind of status. ${ }^{12}$

It would be convenient and theoretically elegant (for the purposes of ethical and legal assessment) if the material realisers of an individual's capacities and powers were always just one's biological constituents and nothing else. Nevertheless, as the foregoing demonstrates, this is in principle treated as an open question, even within the practical domain of law making. It is evident that harm to what underwrites an individual's powers and capacities is a kind of offence with an 
added significance that is absent from mere harm to an individual's property. But the prevailing thought that we can simply circumscribe the material realisers of our personal powers and capacities to the magisterium of biology is one that we may be forced to give up-especially, with the advent of new technologies.

As our daily reliance on certain artifacts becomes increasingly prevalent, it may become impossible to count all extra-organismic possessions as distinct to our personhood, and thereby merely as our property — a thought that can obviously have far reaching implications for the law. Of course, an immediate objection is to say that, absent the relevant theoretical background and practical need for such a reconceptualization of the concept of personal assault, this is just stretching it too far. The above functionalist-looking descriptions of personal assault do not imply anything other than what is obvious... they were introduced as identical to their reductive counterparts, simply because their authors could not possibly imagine that one's person may consist of anything else other than one's biological body.

While this is an appealing line for resisting the possibility of having to reconsider what may count as personal assault, it could be mistaken on both fronts. Over the past three decades, functionalist approaches within philosophy of mind and cognitive science are on the rise, with the approaches of embodied cognition and its more radical consequent, the approach of extended cognition, being at the forefront of studies concerning the workings of the human mind. ${ }^{13}$ Similarly, the emergence of personal computing, and the advent of wearable technologies and the cloud—all of which regularly store personal data automatically, in order to then structure our daily schedules, offer suggestions and monitor our health on a moment to moment basis-have begun to blur the lines between our biological and digital existence. ${ }^{14}$ 
In this paper, we attempt to explore how far these considerations can take us and whether, in certain cases, we should indeed try to legally protect our technological equipment in the same way we do with our biological body parts. In $\$ 2$, we outline the main contours of the extended cognition programme in the philosophy of mind and cognitive science, and note the importance of cognitive integration with respect to whether an external artifact may count as a proper part of a cognitive process. $₫ 3$ draws from the discussion in $\$ 2$ and $\$ 1$ and provides a rationale for embracing as bona fide cases of personal assault cases where what is compromised is, with reference to hypothesis of extended cognition, extra-cranial material realisers of one’s mental faculties. In $₫ 4$, we sharpen this point by studying recent legal and ethical cases that involve damage of what might count as processes of extended memory and extended perception. Finally, in $\$ 5$, we consider further implications of widening our conception of assault in the way suggested, and we explain why it may be a matter of urgent social importance that we do so sooner rather than later.

\section{Cognitive extension}

Consider active externalism (Clark and Chalmers 1998; Menary 2007; Hutchins 1995; Sutton, 2008; Sutton et. al, 2008; Theiner et al., 2010; Wilson 2000, 2004)—a recent advancement within philosophy of mind and cognitive science-according to which, epistemic artifacts such as telescopes, microscopes, pen and paper, Tactile Visual Substitution Systems (TVSS) and other technological equipment may count (under the appropriate conditions) as constitutive parts of one's cognitive system. In other words, epistemic artifacts such as the ones listed above, may occasionally count as literally extending-beyond our brains - the cognitive processes that are thought to make up our minds. 
This is a bold claim, but once we trace its theoretical lineage and motivation it may not sound as implausible as it does on first pass. Active externalism is the extreme consequent of the approach of embodied cognition. In the nineties, several cognitive scientists and philosophers of mind (Varela, Thomson \& Rosch 1991; Clark 1997) as well as roboticists (Brooks 1991a; Brooks 1991b) noted that cognition is embodied in the sense that aspects of the agent's body beyond the brain play a physically constitutive role in cognitive processing (i.e., literally speaking, with respect to several cognitive operations, our bodies are parts of our minds). In particular, for those aspects of an agent's mind where her brain and body are heavily interdependent, we should think of the latter as a constitutive element of the agent's overall cognitive system.

Nearly three decades later, the approach of embodied cognition has come to occupy a central position within philosophy of mind and cognitive science. But if one is willing to accept the embodied cognition hypothesis then they might not be so far from being at least open to the idea of active externalism. No doubt, it might initially be counterintuitive to accept that cognitive systems can extend beyond our organisms to the artifacts we interact with, but the spirit of the approach is very similar to that of embodied cognition. If we are prepared to accept that our minds are embodied when our brains and bodies heavily depend on each other, then there is no principled reason to deny that cognitive processes are extended in those situations where our brains and the artifacts we employ are also heavily interdependent. Indeed, active externalism in all of its forms has been developed, refined, and defended by many philosophers (Clark \& Chalmers 1998; Clark 2007; 2008; Hutchins 1995; Menary 2006; 2007; Theiner 2011; Wheeler 2005, Wilson 2000; 2004), making the approach a viable hypothesis. ${ }^{15}$ 
Here, we will only concern ourselves with what we consider to be the most plausible formulation of the view, known as the extended cognition bypothesis. Focusing on cognitive processing, the hypothesis of extended cognition is the claim that "the actual local operations that realize certain forms of human cognizing include inextricable tangles of feedback, feedforward and feed-around loops: loops that promiscuously criss-cross the boundaries of brain, body and world" (Clark 2007, §2); cognitive processing can and-under the appropriate conditions-literally extends to the agent's surrounding environment. According to the hypothesis of extended cognition, the involved artifacts are proper parts of the ongoing cognitive processing.

But what exactly are the 'appropriate conditions' under which cognitive systems extend beyond the agents' brains and bodies? Answering this question is crucial for determining whether one's approach to active externalism is going to be sufficiently plausible. Of course, here, we do not and cannot wish to argue for the correctness of active externalism, but we believe we should at least provide a strict answer to the above question. By doing so, we will be able to draw the line between what may count as part of one's cognitive system and what not in a clear and perhaps intuitive wayat least to those readers who are well accustomed to using technology on a daily basis. ${ }^{16}$

Several cognitive scientists have recently pointed out that the answer to what may count as a constitutive element of one's cognitive system comes from the mathematical framework of dynamical systems theory (DST) — the most powerful mathematical framework for studying the behavior of dynamical systems in general. According to DST, in order to claim that two systems give rise to some extended process and, thereby, to an overall extended system (or to a coupled system, in DST terms), what is required is the existence of non-linear interactions - that arise out of feedback loops-between the contributing parts (Clark and Chalmers 1998, Chemero 2009, Froese et al. 2013, Sutton et al. 
2008, Theiner et al. 2010, Wegner et al. 1985, Tollefsen \& Dale 2011, Palermos 2014). The underlying rational is that the aforementioned non-linear interactions give rise to an overall integrated system that consists of all the contributing subcomponents.

There are two main reasons for postulating this overall coupled system: (1) The aforementioned non-linear interactions give rise to new systemic properties that belong only to the overall system and to none of the contributing subsystems alone (therefore one has to postulate the overall extended system); (2) Said interactions also make it impossible to decompose the two systems in terms of distinct inputs and outputs from the one subsystem to the other (therefore one cannot but postulate the overall system). Accordingly, the claim, on the basis of DST, is that in order to have an extended cognitive system—as opposed to merely an embedded one (cf., Adams \& Aizawa, 2001, 2010; Rupert, 2004, 2009)—all that is required is that the contributing members (i.e., the relevant cognitive agents and their artifacts) interact continuously and reciprocally (on the basis of feedback loops) with each other. ${ }^{17}$

To appreciate why this might be a plausible approach to cognitive extension, it is interesting to see how it applies in practice. By following the above criterion of cognitive constitution, it is not possible to claim that having our friends' phone numbers stored on our SIM cards or having created a shopping list means that those pieces of information are already parts of our (extended) cognitive systems - in other words, that we remember them in the same way that we remember pieces of information that we have learned by heart. The reason is that there are no non-linear interactions between our intra-cranial cognitive processing and the phonebook or the shopping list. In such cases, there is only one-way, linear dependence between our onboard cognitive capacities and our artifacts, because the processes of storing and retrieving the relevant information do not interact 
reciprocally, but are instead entirely independent of our organismic cognitive processing. We do not affect the artifact but only the other way around. In the light of DST, this sort of dependence does not give rise to a coupled system. Therefore, in such cases, we may only talk of embedded, but not extended, cognition (Rupert, 2004, 2009). ${ }^{18}$

On the contrary, our everyday interaction with telescopes, microscopes, laptops, smartphones and pen and paper when solving complex mathematical problems, the way blind people interact with their canes and Tactial Visual Substitution Systsems would all qualify, as genuine cases of cognitive extension. In such cases, the completion of the relevant cognitive task does involve dense feedback loops between the individual agent and her artifact. ${ }^{19}$ Accordingly, in the light of DST, in such cases, we may indeed have to talk of the presence of an overall extended cognitive system that consists of both the individual agent and her artifact. This, however, may not be such an unwelcome result. ${ }^{20}$ Indeed, we are inclined to think that a growing number of people who have experienced such close technological coupling would, at least, be open to the idea of cognitive extension.

\section{Extended Assault}

Let's now put the pieces together. In $\$ 1$ we identified a common factor to various legal and ethical discussions on personal assault: Personal assault is the intentional harm to a part of a person, which is responsible for her mental and other faculties. In $\$ 2$, we saw that, according to an increasingly popular position embraced in recent philosophy of mind and cognitive science-viz, HEC_-our mental faculties can be partly constituted by external artifacts, so long as these artifacts have been appropriately integrated into our overall cognitive system. Taking these ideas together, what we get is the seemingly radical suggestion that having our integrated epistemic artifacts intentionally 
compromised plausibly qualifies as a case of personal assault. Put more carefully, the argument can be expressed with two premises and a conclusion; call this the Argument for Extended Assault.

Argument for Extended Assault (AEA)

(P1). Intentional harm to a part of a person which is responsible for her mental and other faculties constitutes personal assault. [Definition]

(P2). Our mental faculties can be partly constituted by external artifacts, so long as these artifacts have been appropriately integrated into our overall cognitive system. [from HEC]

(C). Therefore, having our integrated epistemic artifacts intentionally compromised plausibly qualifies as a case of personal assault [From P1 \& P2]

Consider first (P1). Obviously, one may try to reject the claim on the grounds that it is unnecessarily permissive as to what may be the target of personal assault, especially when, for most purposes, it seems perfectly fine to simply point towards one's organismic boundaries. And yet, as we saw in $₫ 1$, an increasing number of legal and ethical theorists appear to steer away from such a reductionist approach to personhood and personal assault, by moving towards a more functionalist understanding of the relevant notions. And this is so, even if they take no stance on the matter of whether the hypothesis of extended cognition is correct_-indeed, in all likelihood, they are entirely unaware of it.

A more straightforward way to avoid the conclusion, therefore, could be to deny (P2), by insisting that the hypothesis of extended cognition is false. Here is of course not the place to adjudicate whether (P2) is actually true or false, and thereby whether AEA is ultimately sound. Rather, the point of AEA is to make explicit that if $\mathrm{HEC}$ is true, then, in light of independently reasonable 
and widely embraced assumptions about what personal assault involves, our ethical and legal theorizing and practice should be prepared to include intentional damage of appropriately integrated gadgets within the category of personal assault—not outside of it.

Moreover, the conditions that our preferred version of HEC specifies may not be so rare to satisfy. On the view we have offered, artifacts are part of our cognitive processing whenever the two of them interact densely on the basis of feedback loops. Of course, whether such biotechnologically hybrid feedback loops will occur rarely or frequently will depend on opportunity conditions such as the availability of appropriate technology and social norms. For example, during the comparatively technologically unsophisticated $17^{\text {th }}$ century, such dense feedback loops were exceedingly rare, perhaps realized in very atypical cases in which an individual would (in a socially unconventional manner) carry around an unwieldy quill, ink and paper for default information storage and retrieval, using it as a sort of prototypical extended memory. ${ }^{21}$ Technological progress has of course shifted dramatically the opportunity conditions for such dense interactions. Correspondingly, the related shift to the social norms associated with cognitive offloading technology (e.g., Lynch 2016) has continued to 'normalize' the heavy use of external artifacts for carrying out cognitive tasks that were so far executed in a primarily intracranial fashion. For example, dense feedback loops between organismic and technological information-processing are now generated on a day-to-day basis, in entirely normal circumstances, with iPhones, tablets, Google Glasses, smart watches, etc. If we also factor in the simple observation that none of these possibilities for cognitive offloading was prevalent or normal even as recently as 10 years ago, then the effect of extrapolation gets even stronger.

And it is not only that there are more possibilities for generating mutually interacting biotechnological hybrids as time goes by. Technological progress also allows them to become 
increasingly subtler and more intimate. Our gadgets are becoming physically and visibly smaller and more discreet. On the basis of well-documented technological trending, it is really just a matter of time before the majority of the cognitive extension gadgetry we use will be by and large seamless and perceptually 'invisible. ${ }^{22}$ A striking example for consideration here is Google's future plans beyond Google Glass, which include the Google 'smart lens' project. The aim is to market 'smart' contact eye lenses with tiny wireless chips inside, and with a wireless antenna thinner than a human hair.

So, if HEC is true, then not only will there be some cases of extended cognition, but there will be increasingly more instances of extended cognition being realized in the world and, eventually, increasingly more instances in which-in real-life settings-our integrated epistemic artifacts might be intentionally compromised.

\section{Two Case Studies}

In some respects, legal thinking is catching up with cognitive science. In others ways, there is important room for improvement. Let's begin with a bit of optimism, though not yet in the arena of assault, per se. Consider the 2014 landmark U.S. Supreme court ruling in Riley v. California. ${ }^{23}$ The background is that David Riley, a U.S. citizen of California, was stopped for a routine traffic violation, but was charged with weapon charges after a police officer searching Riley incident to the arrest had seized Riley's cell phone and found incriminating evidence on it. Riley had moved to suppress all evidence that the police had obtained from his cell phone, however, the trial court denied the motion, and Riley was convicted. The California Court of Appeal affirmed the lower court's ruling.

Nevertheless, in June 2014, the U.S. Supreme Court unanimously overturned the conviction upheld by the California Court of Appeals. Riley's original conviction was based on a legal precedent 
called search incident to arrest (SITA). ${ }^{24}$ SITA permits arresting police officers to perform, without a warrant, search of an arrested person's physical area, which is defined as the area within the person's physical control. ${ }^{25}$ SITA, of course, does not permit a warrantless search of an individuals physical interior (i.e., an investigation of the contents of one's leg, arm, or brain) nor any transgression into her private thoughts (i.e., a mandatory lie detector test, in this circumstance, would be unconstitutional), even though it does permit a warrantless search of the actual physical items in the arrested individual's pockets or of anything he/she may have immediate access to.

Of course, with respect to material constitution, it is natural to treat a cell phone as just another part of the arrested person's 'physical area', as on a par (for the relevance of SITA) with pens, keys and such. However, in Chief Justice John Roberts' written opinion of the Court, he argued that cell phones should be treated very differently in the context of such warrantless searches. His reasoning is interesting and, though Roberts hardly embraces the extended cognition approach in the philosophy of cognitive science explicitly, his remarks in delivering the Court's opinion betray some clear sympathy. Roberts writes:

'[...] modern cell phones ... are now such a pervasive and insistent part of daily life that the proverbial visitor from Mars might conclude they were an important feature of buman anatomy'. ${ }^{26}$

Strikingly, Roberts' assessment here is more or less the same point Clark (2010) makes when defending certain kinds of extended memory, by pointing out the functional similarities between biological parts and well-integrated, technological parts. ${ }^{27}$ A Martian's silicon-based memory system may be made out of different materials (compared to an earthling's memory system) but it would still count as a memory system because it is functionally equivalent to what we, on earth, call a memory 
system. But if an earthling had a smartphone that was made out of the same stuff that the Martian's memory system is made out of and also provided its owner with the same functionality that is provided by both the Martian's and the earthling's biological memory systems, then on what grounds would we deny that the smartphone is part of the earthling's memory system?

Apparently, thinking along similar lines and in lack of a convincing response, Supreme Court Justice Samuel Alito, in his concurring opinion, noted that the changing nature of cell phones' functions and the way we interact with them demands a rethinking of the bounds of SITA; as he put it, modern cell phones now afford an individual an ability to store information 'that no person would ever [sic. previously] have had on his person in hard-copy form.' Of course, what goes for cell phones in this case should go, mutatis mutandis, for similar gadgets, including smart watches, Google Glasses, and in the near future, even Google contact lenses.

To reiterate, Riley vs. California is not a case which establishes (or even purports to establish) that harming an individual's gadgets is a form of personal assault. There is unsurprisingly no such legal precedent, yet. Instead, we register Riley vs. California as a landmark case that features an important shift in legal thinking concerning the technology we densely interact with. And this, we think, is a shift in the right direction: Verdicts like Riley vs. California are important precursors to what we suspect will be a future recognition of the kind of extended assault that (as we argued in $\$ 3$ ) is implied by HEC.

A second case we want to consider shows why a more dramatic shift in thinking is required to accommodate what are-by the lights of HEC—real life extended cognizers. The example we think is most suggestive on this score involves Neil Harbisson, a British artist and cyborg activist who was born with achromatopsia, a condition which left him able to see only monochromatically. 
Despite being born with this condition, colours are no longer imperceptible to him. Harbisson, for the past 10 years, has been able to hear colours, thanks to his 'eyeborg', a device which is osseointigrated inside his skull, specifically his occipital bone, and which converts for Neil visible colours into soundwaves. ${ }^{28}$ He now has a favourite colour: aubergine.

As Harbisson writes:

I started using it 24 hours a day, carrying it around in a backpack and feeling that the cybernetic device, the eyeborg, and my organism were completely connected. I haven't taken it off my head since 2004, except to change the equipment when it breaks ${ }^{29}$.

Interestingly, in 2004 and after some months of initial difficulty, Harbisson's integration of the eyeborg was instrumental in successfully persuading the UK Passport Agency to allow him to include the eyeborg in his passport photo. The passport agency initially insisted he must remove it for the official photo in the same way one is required to remove an electronic device, or a hat, from one's head. However, Harbisson's argument for its inclusion in the photo was, in short, that the eyeborg was a part of his body, not something extra to it-an argument that was supported by his doctor and others with letters to the passport agency. ${ }^{30}$ Harbisson's self-perspective was that 'he became a cyborg when the union between his organism and his antenna created a new sense. ${ }^{, 31}$

The wider legal situation for Harbisson has been more complicated, however. In 2012, police approached Harbisson at a demonstration (believing that he was using his eyeborg to film them), and in the process, tried to pull the device off his head. Now suppose that, in the process, Neil's eyeborg was damaged and, as a result of this, his auditory-colour spectrum was confusingly inverted. ${ }^{32}$ Also suppose that all that was actually damaged in the scuffle was just the eyeborg device, leaving his biological body entirely untouched. Now, with the above in mind, would you say that we should 
regard Neil as having been personally assaulted, or should the inversion of his colour spectrum via intentional harm to the eyeborg be understood along the lines of mere property damage?

We contend that an interpretation of personal assault along the lines of HEC generates the more intuitive answer. It's not hard to see how compromising Harbisson's eyeborg in such a way would be, in all relevant respects, the same kind of harm an individual with otherwise perfectly healthy eyesight would incur, were her colour spectrum confusingly manipulated against her will. Put another way, were Harbisson's eyeborg to have been intentionally corrupted, an assessment of this offense as anything other than personal assault would seem to betray a kind of unprincipled 'bioprejudice', where a disproportionate weight is given to the physical constitution, of the material realisers of one's faculties, over their functional role. After all, the passport agency had already recognized his eyeborg as part of his body, and this is clearly a part of his extended body "responsible for his mental and other faculties."

We compare Riley vs. California and the case of Neil Harbisson because the former shows how legal thinking might be moving in the direction of the conclusion of AEA and the latter shows that failure to embrace its conclusion would seem to generate an unwanted bio-chauvinistic legal and ethical prejudice.

\section{Discussion}

But what is it exactly that we are proposing for consideration? How could a jury plausibly decide that a case of compromising one's gadget counts as a case of personal assault? One way to make this clear is to think about the following case. Subject 1 and Subject 2 have both downloaded and installed an application that turns out to contain some malware that was intentionally planted by a hacker. In result, both laptop operations are fatally disrupted. The only difference is that Subject's 1 laptop is 
brand new - in fact the infected application was one of the very first to be installed-whereas Subject 2 has had his laptop for a couple of years now. During this time, subject 2 has moved the computer's default and customized folders around, has set up shortcuts, mousepad preferences, push-on notifications, he has changed the way folders are ordered, the places where files are automatically stored, he has set up default programmes for opening a number of different files, he has installed an anti-virus programme and configured the preferences, he has set-up ad-blocker exemptions and so on. In this way, subject 2, unlike subject 1, has spent a significant amount of time-perhaps significantly more time than he takes to go to the gym, meditate or see his counselor - in order to tailor his laptop in a way that allows him to fluently carry out the cognitive tasks that he habitually performs on its basis—-many of which plausibly constitute the kind of person that he is. In other words, Subject 2-unlike subject 1 - has set up all these small details that allow him to mutually interact with his laptop in a continuous and fluent way, which-by the lights of HEC - is a clear indication that the two systems constitute an extended cognitive system. Accordingly, if AEA goes through to its conclusion, the result is that subject 2-unlike subject 1-is the victim of (extended) personal assault, because the damaged laptop does not constitute mere property for him, but is part of the cognitive machinery that makes up the kind of person that he is.

In other words, the suggestion is this: Just as in the case of cognitive extension so in the case of (extended) personal assault, whenever an individual's mental powers and faculties rely for their operation on continuous mutual interactions between some of the individual's organismic faculties and some artifact of hers, we have sufficient indication that the relevant person-and her legal and ethical rights against personal assault — should be extended to include the involved artifacts. ${ }^{33}$ 
An anticipated objection to this approach is to point out that the involved artifacts are not really parts of one's person, because, unlike real body parts, they can be easily replaced by brand new ones. Initially this may be a tempting response, but it is one that is ultimately bound to fail. If anything, it has the somewhat disconcerting - to say the least-implication that once bionic limbs become as functionally successful as real limbs, then serious and intentional bodily injury-one that could potentially lead to amputation-would be downgraded from counting as personal assault to counting as mere damage of personal property.

Of course, it is possible to further insist on the difference between organismic body parts and external artifacts, by noting that biological body parts, unlike electronic devices, are not mere hardware that runs on some behavior-guiding digital software that can be easily stored on the cloud any time we like. Biological body parts also have a number of analogue features (like muscle memory) whose dynamic status continuously feeds back to one's physiological, peripheral and central nervous system. Such analogue features, however, could not be backed up or replicated as easily as the state of your laptop's operating system. This is a very interesting objection, a reply to which can reveal a number of instructive observations.

First off, even though most contemporary information-processing artifacts operate mainly on the basis of their digital features — with the parameters of their analogue features remaining static and entirely unaffected throughout the operation of the software- this is far from a necessary feature of technology, and it is most likely bound to change. Just like our body parts, so the functionality of future technologies is not going to depend merely on the basis of a set of digital rules inscribed, say, on the motherboard of the relevant technological machinery, but instead on the dynamic interplay between these digital instructions, the artifact's continuously responsive and highly malleable 
analogue features and the physiological and neurological functions of the whole organism. In result, in the near future, restoring the functionality of one's damaged but previously highly personalized equipment is not going to be possible simply by replacing it with the default hardware equipment and returning the underlying software to the state it was in before it was damaged. The new hardware will also have to be restored to the analogue — and highly idiosyncratic to its user-state it was in before the assault. But while an artifact's digital state might be easy to replicate, it is very likely that this is not going to be the case with respect to its analogue nature, mainly for practical reasons concerning the originating factory's production line. Indeed, it is highly unlikely that factories could physically tailor their products to match the needs of their customers individually. What is more likely is that they would make their products plastic enough so that each user could extensively calibrate them to match their own needs.

Moreover, while the above pertain exclusively to the status of the external artifacts, we must not forget that the equation also includes the brain and body of the organismic agent. The appropriate integration of any piece of equipment most certainly involves a number of changes to one's physical body, with the most important being no other than the rewiring of one's own brain so that it can fluently interact with the external equipment. Therefore, the treatment of future cases of disrupted cognitive extension will require that one bring the overall (extended) system back to its previous state of mutual dynamic interaction between all components. Most likely, this is going to involve a form of 'technotherapy' (with cognitive rehabilitation being only a sub-component of the overall treatment) that could potentially be as long and distressing as the physiotherapies one has to undertake after an accident or operation. 
Granted, as far as current technologies are concerned, reintegrating one's artifacts is not as time consuming and stressful as it might once be in the future. For the time being, most of our equipments' personalized functionalities depend merely on the underlying software, which can be easily backed up in the cloud, such that one's new laptop can, within a matter of few hours, run in the exact same way as one's old laptop. As noted in the foregoing, this is merely a contingent matter of fact that is most likely going to change in the near future, but what are the lessons we can draw from it for the current state of play?

It is not difficult to imagine that the opponent of the argument for extended assault is going to take advantage of this contingency by claiming that, for the time being, damaging one's hardware equipment cannot possibly count as a case of personal assault, simply because its hardware can be replaced and its software easily backed up. While this is true, it does not really speak to the heart of the matter we are here concerned with, but simply transfers the problematic from the hardware to the online world. For while our hardware equipment is an easily replaceable — at least for the time being-supervenience base that supports our operating systems, the state of these software operating systems is crucial for the appropriate, cognitive integration of our technological equipment. In cases where it is possible to back up one's software online — and note that this is not always possible-we might indeed be able to stop worrying about whether extended personal assault could apply to one's hardware equipment. This is not so, however, with respect to cyber attacks against our online personal accounts—like one's Google or Apple account—and against the back-up of our operating systems and information on the cloud.

Even if-for the time being-we may stop worrying about whether damage of one's hardware should constitute a case of personal assault, it seems that it is not easy to employ as lenient 
an approach towards cyber-attacks against our online accounts and cloud back-ups. And this should not be of concern only to hackers but also major companies such as Google, Microsoft and Apple. For if our cloud accounts are part of who we are, then we should also expect such companies to be legally bound and responsible toward their users in ways that have, perhaps, so far been significantly underestimated. ${ }^{34}$

As the recent case between Apple and the F.B.I. demonstrates, some of these companies (e.g., Apple, Google, Whatsapp, Twitter, etc.) appear to be sensitive to this sort of responsibility and they seem willing to protect their user's privacy and safety against cyber attacks even on the face of potentially serious legal costs. The good news is that, according to the above considerations, such companies may now have one more argument to offer against the F.B.I. and White House's demands: Assuming that the Argument for Extended Assault is correct, then, by hacking its own operating system, Apple won't only expose its users to potentially having their personal property damaged, but it will also make them subject to the far greater risk of being personally assaulted by anyone who might get hold of the controversial key. ${ }^{35}$

Of course, to return to an observation we made earlier, whether one's intuitions are going to align with such a conclusion-and, more generally, with the conclusion of the Argument for Extended Assault—depends on the extent to which technology has already penetrated one's everyday life. Nevertheless, before we allow ourselves to draw any conclusions based on our own, personal and thereby limited experience, it is perhaps also worth considering that, sometimes, integrated technology can play a central role in the well-being of some people who couldn't possibly survive without it. 
While everyone may agree that having our smartphones or laptops severely compromised might feel like a great (personal) loss, to most of us it is still a kind of loss that, given enough time, effort and resources, we can hope to get past without worrying that our well-being is going to be severely threatened in the process. Nevertheless, as films such as Still Alice have recently brought to popular attention, there is a part of the population for which technology plays a central and largely irreplaceable role. There are numerous stories of people who, after having suffered irreversible brain damage or being the victims of dementia, ${ }^{36}$ use their smartphones and social media accounts as substitutes for their long and short term memories — a fact that is clearly mirrored by the emergence of an increasing number of applications designed to help such patients. ${ }^{37}$ For them, their integrated technology really is a central aspect of who they are and what they can do, supporting their personal autonomy to an extent that few, if any, of us can fully appreciate. ${ }^{38}$

\section{Concluding Remarks}

Contrary to what the above dialectics may suggest, we would like to close by pointing to a moderate direction. Our aim has not been to suggest that accepting the Argument for Extended Assault should be the way forward. Rather, this paper is an attempt to demonstrate that, given (1) current legal as well as normative ethical theorizing, (2) recent advances within cognitive science and (3) the rapidly growing and penetrating use of technologies, the idea of extended personal assault is at least worthy of serious consideration. This is admittedly an early idea that more needs to be said in its defense. Nevertheless, we hope to have here demonstrated that making a case for it is possible. This is a possibility, which even if it turned out to be wrong, would still require a thorough understanding of 
its motivation and rationale. Especially when the exponential progress of technology is about to enter its steep curve. ${ }^{39}$

\section{References}

Adams, F. \& Aizawa, K. (2001). 'The Bounds of Cognition'. Philosophical Psychology 14 (1): 43-64.

- (2008). The Bounds of Cognition. John Wiley \& Sons.

- (2010). 'The Value of Cognitivism in Thinking about Extended Cognition'. Christman, J. (2015). 'Autonomy in Moral and Political Philosophy', in The Stanford Encyclopedia of Philosophy, edited by Edward N. Zalta.

Baker, L.R. (2000). Persons and Bodies. Cambridge: Cambridge University Press.

Block, N. (1980). Troubles With Functionalism, Readings in the Philosophy of Psychology, Volumes 1 and 2, Cambridge, MA: Harvard University Press

Bostrom, N., \& Savulescu, J. (2009). 'Human Enhancement Ethics: The State of the Debate', Human Enhancement, (eds.) N. Bostrom \&J. Savulescu, 1-22, Oxford: Oxford University Press.

Brooks, R. (1991a). 'Intelligence without Representation', Artificial Intelligence 47, 139-59.

_ (1991b). 'Intelligence without Reason', Proceedings of 12th International Joint Conference on Artificial Intelligence, 569-95.

Clark, A., \& Chalmers, D. (1998). The extended mind. Ananlysis, 58(1), 7-19.

Clark, A. (1997). Being There: Putting Mind, Body, and World Together Again, Cambridge, MA: MIT Press.

Clark, A. (2008). Supersizing the Mind: Embodiment, Action, and Cognitive Extension. Oxford: Oxford University Press.

Clark, A. (2009). Spreading the joy? Why the machinery of consciousness is (probably) still in the head. Mind, 118(472), 963-993. 
- (2010). 'Memento's Revenge: The Extended Mind Extended'. In The Extended Mind, edited by Richard Menary, 43-66. MIT Press.

Clark, A. \& Chalmers, D. (1998). 'The Extended Mind'. Analysis 58 (1): 7-19.

Clowes, R. W. (2012). Hybrid memory, cognitive technology and self. InProceedings of the 5th AISB Symposium on Computing and Philosophy (pp. 4-13).

Chemero, A. (2009). Radical Embodied Cognitive Science, Cambridge, MA: MIT Press.

Cohen, G.A. (1995). Self-Ownership, Freedom and Equality. Cambridge: Cambridge Univeristy Press.

Froese, T., Gershenson, C., \& Rosenblueth, D. A. (2013). 'The Dynamically Extended Mind', available at: http://arxiv.org/abs/1305.1958.

Gray, C.H. (1995). ed. The Cyborg Handbook. New York: Routledge.

Heersmink, R. (2015a). Dimensions of integration in embedded and extended cognitive systems. Phenomenology and the Cognitive Sciences, 14(3), 577-598.

Heersmink, R. (2015b). Extended mind and cognitive enhancement: moral aspects of cognitive artifacts. Phenomenology and the Cognitive Sciences, 1-16.

Heersmink, R. (2016). Distributed selves: personal identity and extended memory systems. Synthese, 1-17.

Heersmink, R. (forthcoming). Distributed cognition and distributed morality: Agency, artifacts and systems. Science and Engineering Ethics, 1-18.

Hoven, E., Cas, C., \& Whittaker, S. (2012). Introduction to this special issue on designing for personal memories: Past, present, and future. Human-Computer Interaction, 27(1-2), 1-12.

Howard-Snyder, F. (2011). 'Doing Vs. Allowing Harm', in The Stanford Encyclopedia of Philosophy, edited by Edward N. Zalta. Winter 2011.

Hutchins, E. (1995). Cognition in the wild. Cambridge: MIT Press

Kiverstein, J. \& Farina, M. 2012. Do sensory substitution devices extend the conscious mind? In F. Paglieri (Ed) Consciousness in interaction: the role of the natural and social context in shaping consciousness. John Benjamins Publishing. pp.19-40.

Levin, Janet, "Functionalism", The Stanford Encyclopedia of Philosophy (Fall 2013 Edition), Edward N. Zalta (ed.), URL = <http://plato.stanford.edu/archives $/$ fall2013/entries/functionalism/>.

Lynch, M. (2016). The Internet of Us. Liveri.ght Publishing Corporation, New York 
Menary, R. (2006). 'Attacking the Bounds of Cognition'. Philosophical Psychology 19 (3): 329-44.

Menary, R. (2007). Cognitive integration: Mind and cognition unbound. Basingstoke: Palgrave McMillan.

Miah, A. \& Rich, E. (2008). The Medicalization of Cyberspace. London: Routledge.

O'Hara, K., Tufflied, M.M.,\&Shadbolt, N. (2008). Lifelogging: Privacy and empowerment with memoriesfor life. Identity in the Information Society, 1(1), 155-172.

Palermos, S. O. (2014a). Loops, constitution, and cognitive extension. Cognitive systems research, 27, 2541.

Robb, K. (1994). Literacy and Paideia in Ancient Greece. Oxford: Oxford University Press, 1994.

Rupert, D. R. (2004). 'Challenges to the Hypothesis of Extended Cognition', Journal of Philosophy 101, 389-428.

— (2009). Cognitive Systems and the Extended Mind, Oxford: Oxford University Press.

Sprevak, M. 2009. "Extended cognition and functionalism", fournal of Philosophy 106: 503-527.

Sutton, J. (2008). Between individual and collective memory: Coordination, interaction, distribution. Social Research, 75(1), 23-48.

Sutton, J., Barnier, A., Harris, C.,\&Wilson, R. (2008). A conceptual and empirical framework for the social distribution of cognition: The case of memory. Cognitive Systems Research, 9, 35-51.

Taylor, C. (1991). The Ethics of Authenticity. Cambridge: Cambridge University Press.

Theiner, G. (2011). Res Cogitans Extensa: A Philosophical Defense of the Extended Mind Thesis, Bern, Switzerland: Peter Lang GmbH, Europaischer Verlag der Wissenschaften.

Theiner, G., Allen, C., \& Goldstone, R. (2010). Recognizing group cognition. Cognitive Systems Research, 11(4), 378-395.

Tollefsen, D., \& Dale, R. (2011). 'Naturalizing Joint Action: A Process-Based Approach', Philosophical Psychology 25, 385-407.

Varela, F., Thompson, E., \& Rosch, E. (1991). The Embodied Mind: Cognitive Science and Human Experience, Cambridge, MA: MIT Press.

Wegner, M., Giuliano, T., \& Hertel, P. (1985). 'Cognitive Interdependence in Close Relationships',

Compatible and Incompatible Relationships, (ed.) W. J. Ickes, 253-76, New York:

Springer-Verlag.

Weiskopf, D. 2008. "Patrolling the mind’s boundaries", Erkenntnis 68: 265-276. 
Wheeler, M. (2005). Reconstructing the Cognitive World, Cambridge, MA: MIT Press.

Wheeler M (2010). In Defense of Extended Functionalism. In: Menary R (ed.). The Extended Mind.

Life and Mind series: Philosophical Issues in Biology and Psychology, Cambridge, MA, USA: MIT Press, pp. 245-270.

Wilson, R. A. (2000). The mind beyond itself. InD. Sperber (Ed.), Metarepresentations: A multidisciplinary perspective (pp. 31-52). New York: Oxford University Press.

Wilson, R. (2004). Boundaries of the mind: The individual in the fragile sciences: Cognition. New York: Cambridge University Press.

\section{NOTES}

${ }^{1}$ Authors names appear in alphabetical order

2 Two contemporary strands of research clustering around this question engage with slightly different aspects of it. On one hand, philosophy of mind and cognitive science (e.g., Clark and Chalmers 1998; Clark 2010) focuses on the metaphysical status of our gadgets: for example, could information stored in our gadgets qualify as part of our minds, literally speaking? An affirmative answer to this question has been labeled the 'extended mind thesis' (e.g., Clark and Chalmers 1998). On the other hand, bioethics focuses on the ethics of human enhancement (e.g., Bostrom \& Savulescu 2009) exploring the normative dimensions of the phenomenon: for example, is intelligence augmentation a good thing and under what forms?

${ }^{3}$ See, for example, Fagan versus Metropolitan Police Commissioner (1968). The present discussion of harm will not turn on any substantive claim about how to distinguish doing versus allowing harm. For discussion on this point, see HowardSnyder (2011).

4John Locke's political philosophy in Two Treatises of Government is famously derived from the principle of self-ownership, which features as well in the 13th Amendment to the United States Constitution.

${ }^{5}$ The violation of one's bodily integrity through intended force is protected against by both the UN General Assembly's Universal Declaration of Human Rights and the International Covenant on Civil and Political Rights.

${ }^{6}$ For instance, features of intent are important in distinguishing between, for instance, simple assault and aggravated assault.

${ }^{7}$ Lord Hobhouse, Regina vs. M. Chan Fook.

8 Within philosophy of mind, functionalism is the doctrine that what makes something a mental state of a particular type does not depend on its internal constitution, but rather on the way it functions, or the role it plays, in the system of which it is a part. As such, functionalism denies that the essence of a mental state can be identified with a particular material basis. A mental state may be realised by any material or non-material (functionalism is neutral between dualism 
and materialism) basis, so long as the basis under consideration gives rise to the kind of function that the target mental state is identified with. Functionalism's denial to identify mental states with a specific underlying basis is supposed to be one of the view's main advantages, because it allows for the phenomenon of multiple realizability: Creatures with organisms unlike ours can share our sensations, beliefs, and desires, provided that their behavior and functional organization is similar to our own. Thus functionalism provides a more inclusive theory of mind that avoids specieschauvinism (Block 1980). For more details, see (Levin 2013).

9 Our italics.

${ }^{10}$ Even though the above quote points only to what is outside the agent's control, Taylor's work clearly indicates that by that he also means what could lie even outside the agent's organism. See for example Taylor's treatise on personhood Sources of the Self (1989, e.g., p. 34). Cf., Lynne Rudder Baker (2000) for another expression of the idea that personhood and the biological organism can come apart.

${ }^{11}$ As John Christman (2015) notes, for example, we can't reflect on our own values and goals without language, and yet language is itself a social product. For this reason, it's a mistake to, as Christman puts it, 'say that we are autonomous (and hence morally responsible, bear moral rights, etc.) only when we can step back from all such connections and critically appraise and possibly alter them flies in the face of these psychological and metaphysical realities’ (2015, \$3.2).

12 One line of resistance here, suggested by an anonymous referee, proceeds as follows: personal harm is a special category of offence in part because persons are phenomenally conscious ('sentient') creatures capable of experiencing pain, and normally, if someone damages part of another's biological body, that individual is pained by the damage. So, absent a further argument for extended consciousness which could in turn ground extended sentience, an 'asymmetry' remains (considerations against the possibility of extended consciousness can be found in Clark 2009; for an interesting argument in its support, see Kiverstein and Farina 2012). The referee anticipates that one line of response would be to insist that (for example) neuro-prosthetic limbs restore sensation to amputees and lets them 'feel' objects with, say, their bionic hand as if they were part of their body rather than a mere tool; similarly, the loss of a highly integrated smartifact may be experienced more like the loss of a vulnerable biological limb than that of a replaceable tool. Nevertheless, this kind of anticipated rejoinder (which the referee notes is itself potentially problematic) is not one we would be inclined to take. This is because intentionally caused pain is not essential to personal harm'; rather, it is merely a typical sufficient condition for it. For example, sexual crimes committed against unconscious victims are paradigmatic cases of personal harm that are categorised as assault. We thus are inclined to deny the premise that the phenomenology of extended assault must mimic the phenomenology of harm to one's physical body, rather than to accept the premise and argue that the phenomenology of harm to one's extended parts is on a kind of par with the phenomenology of harm to one's biological parts. We thank an anonymous referee for pressing us on this point.

13 Several theorists have commented on the affinity between functionalist approaches to philosophy of mind and the hypothesis of extended cognition. Consider Weiskopf (2008), for example, who submits that "functionalism has all 
along been committed to the possibility of extra-bodily states playing the role of beliefs and desires" (267). See also Sprevak (2009) and Wheeler (2010).

${ }^{14}$ Consider for example autobiographical memory technologies known as “lifelogging technologies” (O’Harra et al. 2008; Hoven et al. 2012).

15 Which is not to say that the view is without its critics. Even though the discussion of the objections facing active externalism is well beyond the scope of the present paper, briefly, many of them point either to the dissimilarity between the inner cognitive processes and the external elements that are supposed to be parts of one's cognitive system (e.g., Rupert 2004; Adams \& Aizawa 2008), or to the perceptive rather than introspective manipulation of those external elements. Others deny the mark of the cognitive to the alleged extended cognitive processes (e.g., Adams \& Aizawa 2008), or claim that there cannot be a science of active externalism (e.g., Rupert 2004; Adams \& Aizawa 2008). For a short discussion and reply to most of these objections, see Menary (2006).

${ }^{16}$ In our personal experience, computer scientists are surprisingly receptive to the hypothesis of extended cognition.

${ }^{17}$ For more details on how dynamical systems theory can help distinguish between the hypothesis of extended cognition and the hypothesis of embedded cognition as well as avoid several other worries with respect to the hypothesis of extended cognition (e.g., the 'cognitive bloat' worry and the 'causal-constitution' fallacy), see (Palermos 2014).

18 An anonymous referee points out that the distinction between embedded and extended cognition might be viewed as a continuum, with cognitive extension occupying one of the extremes. How close to that extreme a given case may lie could then be decided on the basis of several factors. For example, while avoiding offering any necessary and sufficient conditions on cognitive extension, Heersmink (2015a) draws and expands on Clark and Chalmers' (1998) 'glue and trust' criteria in order to offer a way to decide whether a case may plausibly count as a case of cognitive extension. Specifically, Heersmink offers the following dimensions of cognitive integration: information flow, accessibility, durability, trust, procedural transparency, informational transparency, individualization and transformation. Depending on how high an agent's relation to her artifact scores along these dimensions, the more confident we can be that we face a genuine case of cognitive extension. While this an interesting approach that can offer some indication as to whether employing an artifact may qualify as a case of cognitive extension, its weakness lies in that, as Heersmink himself acknowledges, it does not provide a set of necessary and sufficient conditions on cognitive extension, which is very important for the paper's present purposes - deciding whether damaging one's property may count as a case of personal assault requires a clear and strict condition on cognitive extension. Nevertheless, as one of us has extensively argued in the past (Palermos 2014), relying on such 'glue and trust' criteria is not entirely unrelated to the present approach: According to (Palermos 2014), while none of the above 'glue and trust' requirements is necessary or sufficient on its own, in most practical contexts, they will constitute practical preconditions in order for ongoing mutual interactions to arise between the agent and her artifacts. This means that if an agent's continuously and mutually interacts with her smartifact - i.e. the only necessary and sufficient condition on cognitive extension, according to DST - then we can assume that she will also score high with respect to most of 
the dimensions of cognitive integration that Heersmink suggests. In fact, in the following concluding passage of his paper, Heersmink (2015a, 595) appears to make the exact same point:

In one corner of this multidimensional space we find systems with a high-bandwidth reciprocal information flow, where the artifact is reliably available, the relation between agent and artifact is durable, the information it provides is trustworthy, the artifact is procedurally and informationally transparent, it is individualized or possibly even entrenched, and its representational systems has transformed the brain of it user. These are obvious cases for extended and distributed cognitive systems. In another corner of this space we find systems that score low on all these dimensions. These are clear cases for embedded systems.

${ }^{19}$ Take for example the case of telescopic observation. Making telescopic observations qualifies as a case of cognitive extension, because it is a dynamical process that involves ongoing reciprocal interactions between the agent and the artifact. Moving the telescope around, while adjusting the lenses, generates certain effects (e.g., shapes on the lens of the telescope), whose feedback drives the ongoing cognitive loops along. Eventually, as the process unfolds, the coupled system of the agent and his telescope is able to identify — that is, see — the target satellite.

${ }^{20}$ Notice that the 'continuous and reciprocal interactions' criterion on cognitive extension does not distinguish between low- and high-tech cases. As indicated in the main text, while shopping lists may be excluded, low-tech cases such as using pen and paper to solve a mathematical problem or a blind man's cane would qualify as cases of cognitive extension. One interesting question, however, concerns the case of the Alzheimer's patient, Otto, and his notebook (Clark and Chalmers, 1998), which is used in order to store and retrieve information that would otherwise be stored in Otto's biological memory. This is one of the typical examples of cognitive extension presented in the literature, but given that scribing information on one's notebook is similar to writing shopping lists, it appears that the suggested criterion of 'continuous and reciprocal interactions' may exclude this well-known example. We want to suggest that it all depends on how we read the example. If we imagine Otto as being very well trained and organized, constantly having his notebook open, going back and forth over its pages, looking up its contents as well as taking notes about almost every single detail that would normally be registered in his biological memory, then he does continuously and mutually interact with his notebook, such that, in light of DST, it would count as a case of cognitive extension.

21 A much earlier example, from ancient Crete, involves the use of a $M n \bar{e} m \bar{o} n$, or 'rememberer', who would play the role of a scribe (poinikastas) for another individual. However, this falls within the bounds of a distributed cognitive system, or perhaps a transactive memory system, as opposed to an ordinary case of extended cognition. For discussion of early cases of such use of Mnēmōn scribes, see Robb (1994).

22 See, along with Lynch (2016), a review of Bostrom and Sandberg (2009) for discussion of some of the latest intelligence augmentation possibilities. 
23 For helpful discussion of this case, see http://www.natlawreview.com/article/landmark-supreme-court-rulingprotects-cell-phones-warrantless-searches. For the official U.S. Supreme Court opinion, see http://www.supremecourt.gov/opinions/13pdf/13-132_819c.pdf

${ }^{24}$ For an overview of SITA precedent in U.S. law, see http://law.justia.com/constitution/us/amendment-04/14-searchincident-to-arrest.html

25 See U.S. vs. Rabinowicz (1950).

26 Our italics. Roberts adds, in his discussion, that "Modern cell phones are not just another technological convenience. With all they contain and all they may reveal, they hold for many Americans "the privacies of life". The fact that technology now allows an individual to carry such information in his hand does not make the information any less worthy of the protection for which the Founders fought."

27 As Clark (2010b) remarks, one who satisfies integration conditions by using a notebook to compensate for failing biological memory 'is so used to using the book that he accesses it automatically when bio-memory fails. It is transparent equipment for him just as biological memory is [sic. in the default case].'

${ }^{28}$ For more about Neil, you can see his TED talk here: https://www.youtube.com/watch?v=ygRNoieAnzI\#t=49

29 For detailed reports of the story see http://www.bbc.co.uk/news/magazine-16681630, and http://www.theguardian.com/artanddesign/2014/may/06/neil-harbisson-worlds-first-cyborg-artist

30 Miah \& Rich (2008).

31 Serra, L. (2011). http://www.ara.cat/societat/No-blancs-negres-tots taronges_0_411558847.html

32 Compare with a related notable incident, involving Steve Mann, developer of the Eye'Tap Digital Eye Glass, who was assaulted in a McDonalds in Paris, France, when an employee of McDonalds attempted to remove Mann's Digital glass eye. http://www.webcitation.org/6DGSr4dBe

${ }^{33}$ It's important to note that the legal protection afforded to individuals with cognitively integrated artifacts will be, in typical cases, legal protection for individuals with faculties best understood as restored to normal baseline levels of functioning rather than enhanced (Gray 1995). Following Bostrom \& Savulescu (2009, 310) we can distinguish between therapeutic cognitive improvements, which are aimed at correcting a specific pathology or cognitive defect (e.g., treatments aimed at slowing the progression of Alzheimer's) and cognitive enbancements which are (roughly) interventions that improve cognitive functioning nontherapeutically (e.g., by ways that do not involve the repairing of a cognitive defect or dysfunction). This distinction is relevant because, to the extent that one suggests that the legal protection for enhancements should be evaluated differently to legal protection for therapentic improvements, cases like Harbisson's and also Mann's (see fn. 23) belong in the latter rather than the former category.

${ }^{34}$ Focusing on the claim that cloud accounts can be part of who we are, an anonymous referee wonders whether cognitive extension implies extended personhood. This is an interesting question but the present dialectics do not require that we address it directly. The reason is that AEA does not claim that personal assault can be extended because personhood is extended. Instead, relying on relevant ethical and legal theorizing, AEA claims that personal assault extends because the mental faculties that constitute one's person are extended. Accordingly, in order to make the case for 
AEA we only need to show that, plausibly, one's mental faculties can be extended. We believe that the DST approach to cognitive extension sufficiently demonstrates that. As a side note, however, it is worth noting that while some theorists reject the move from extended cognition to extended personhood (Baker 2009, Olsen 2011 and Buller 2013), a number of philosophers of mind-including Clark and Chalmers (1998), Clark (2007), Clowes (2012) and, in series of interesting papers on the related topic of extended morality, Heersmink (2015b, 2016, forthcoming ) —all argue for the possibility of extended personhood. Therefore, arguments for extended personal assault could also be convincingly motivated on the basis of extended personhood.

35 Very worryingly, and in relation to the discussion of the above paragraph, the Guardian (http://www.theguardian.com/technology/2016/feb/20/apple-fbi-iphone-explainer-san-bernardino) notes that data stored on the cloud "are much easier for the FBI to obtain; Apple can't make the case that it doesn't have immediate access to them because they're stored on Apple's own computers." If the above analysis is correct, however, then data saved on one's cloud account are also part of one's person and should be legally protected in the same way as data stored in one's physical devices.

36 Think for example, of Ricky Dean who was left with no short or long term memory after his brain was starved of oxygen shortly after his birth (http://www.dailymail.co.uk/news/article-2388458/The-boy-remember-Every-morningRicky-wakes-memory-day-needs-notes-tell-brush-teeth-meet-friends.html) or Thomas Dixon who suffers from a severe impairment to his episodic memory after being hit by a car (http://www.fastcompany.com/3037432/this-man-usestwitter-as-a-prosthetic-device-for-his-damaged-memory).

37 The following websites contain some indicative examples:

http://www.qcare.co.uk/top-5-apps-for-people-living-with-dementia.html

http://appcrawlr.com/ios-apps/best-apps-term-memory-loss

http://memoryappsfordementia.org.uk

38 An anonymous referee notes that it would be interesting to speculate whether the present argument for extended personal assault generalizes to the case of collective cognitive systems, which include among their proper (cognitive) parts people with individual minds (cf. Theiner et al. 2010). It has been shown in the relevant literature that groups of people such as couples, infant and caretaker, blind person and dog, but also families, work teams, and even larger social organizations are often dynamically coupled, in systematic two-way interactions whose density and degrees of coadaptation outstrip our reliance on present or even near-future technologies. If any human components of a socially distributed cognitive systems in which person $\mathrm{P}$ actively participates are removed, should we equally count that as a 'personal assault' of $\mathrm{P}$ ? This is admittedly a very interesting question that deserves to be explicitly addressed in the future. However, due to space limitations and since the present paper is primarily concerned with the legal ramifications of damaging one's artifacts we have to restrict ourselves in speculating that such cases should indeed count as cases of personal assault, especially when the dissolution of the collective cognitive system does not comply with the will of all involved parties. For example, even though the law does not treat cases of non-consensual divorces as cases of personal assault, the fact that consensual divorces are much easier to issue could in part indicate that this intuition is justified. 
39 We are thankful to Panagiotis Kourtesis for his thoughtful comments on a previous draft of the paper. We would also like to thank the audiences of the IT Futures Conference (University of Edinburgh, December 2014) and the Extended Knowledge Impact Event (January 2016), where previous versions of the paper were presented and discussed. This paper was produced as part of the AHRC-funded 'Extended Knowledge' research project (AH/J011908/1), which was hosted at Edinburgh's Eidyn Research Centre. 